\title{
Mixed Type Basal Cell Carcinoma in 48 Years Old Caucasian Male: A Case Report
}

\author{
Suma Pratiwi Tanoto ${ }^{1}$, Gusti Ayu Vina Mery Giovani ${ }^{2}$ \\ ${ }^{1,2}$ Department of Dermatology and Venerology, Siloam Hospitals Denpasar, Denpasar, Bali-Indonesia \\ Corresponding Author: Suma Pratiwi Tanoto
}

DOI: https://doi.org/10.52403/ijrr.20220235

\begin{abstract}
Introduction: Basal cell carcinoma (BCC) is a malignancy which often affects white-skinned people. The incidence increased in the world up to $10 \%$ per year. Ultraviolet exposure is the most common risk factor, and usually affects head and neck. Patients with BCC have increased risks of having melanoma but no other internal malignancy. The existence of lumps which easily bleed and hard to heal perfectly is the most common symptoms found. Diagnosing it is based on the description of the lesion and the result if skin's histopathology examination. Management is a very important aspect because if it is not treated, it will invade the surrounding tissue and result in functional and cosmetic disturbance.
\end{abstract}

Objective: To describe the clinical relevance regarding symptom, dermoscopy examination and treatment of basal cell carcinoma.

Case Report: A 48-year-old male complained of having a wound on his left shoulder since a year before. At the beginning the lesion was small and red, then gradually grew larger and black. Patient did not admit having the same complaint before and there was no history of disease or malignancy. $\mathrm{He}$ also done dermoscopy examination which is the result led to basal cell carcinoma characteristics. Excision wound on his left shoulder was done and the histopathology result came as a mixed type basal cell carcinoma.

Discussion: Based on anamnesis, physical and diagnostic examinations, the working diagnosis of this patient was mixed type basal cell carcinoma. Diagnostic test is carried out by dermoscopy and histopathology examination. From the dermoscopy examination, it was found that the result was consistent with the characteristic of basal cell carcinoma. The histopathology result also confirmed that the cells were matched with the description of basaloid cells arranged palisades at the edge. The skin's condition had to be evaluated in the next six months.

Conclusion: Basal cell carcinoma is a common malignancy which happens most often in whiteskinned people who are exposed to ultraviolet regularly. It is very important to check skin's condition if a suspicious lump is present. The management is a crucial aspect needed to prevent invasions to surrounding tissues.

Keywords: basal cell carcinoma, skin tumor, local invasion

\section{INTRODUCTION}

Basal cell carcinoma (BCC) is a slow growing, locally invasive malignant tumor originating from the basal cells of epidermis. Generally, the incidence increases by $3 \%-10 \%$ annually. ${ }^{1}$ It is mostly found in Caucasian population, elderly people and male. The incidence of BCC in Australia is $>1,000 / 100,000$ people per year. ${ }^{2}$ In Japan, the incidence is $50 \%$ of the skin malignancy. In Indonesia, there were 181 cases $(43.3 \%)$ of basal cell carcinoma in five years (2005-2009). ${ }^{3}$

The most common risk factors of $\mathrm{BCC}$ are exposure to ultraviolet, indoor tanning, history of skin malignancy in the patient, family, arsenic exposure, history of smoking and immunosuppression. Ultraviolet (UV) exposure is the main cause basal cell carcinoma, So the predilection is the area of the body that is often exposed to 
ultraviolet (UV), especially in the face, ears, and neck area., ${ }^{7,8}$ BCC has several typesnodular, pigmented, superficial, morpheaform, and fibroepithelioma of pinkus. Histopathology examination is a gold standard test for BCC. However, this examination is invasive, expensive, and takes a long time to perform the result. Histopathology of BCC is also varied according to its type. ${ }^{1}$ Other supporting examination for BCC that are not invasive, easy to do, inexpensive and the results can be known directly, is by dermoscopy examination. ${ }^{9}$

Dermatologist can make an early diagnosis of BCC and another pigmented lesions of the skin with dermoscopy. Dermoscopy is an in vivo method that requires optical magnificent and liquid immersion. Specially designed handheld devices with 10 to 20 times magnification. The sensitivity of dermoscopy in making diagnosis reaches $95-97 \%$ and the specificity reaches $87-96 \%$, so that dermoscopy can be a routine examination in patients with suspected BCC. The characteristics of the dermoscopy structures that can be found in BCC are arborizing vessels, ulceration, multiple small erosions, blue-gray ovoid nest, superficial fine telangiectasis, multiple blue-gray dots/globules, maple leaf-like areas, and spoke wheel areas. ${ }^{9}$ The important things when make a diagnosis of pigmented BCC is based on the absence of pigment network and the presence of at least one of the dermoscopic features found. ${ }^{10}$ Criteria for high-risk basal cell carcinoma when the lesion $>2 \mathrm{~cm}$ size with ill-defined margins, recurrent tumours, immuno-suppressed individuals and the location near the eye,nose, ear $^{6}$

BCC can be diagnosed with the presence of skin biopsy. There are several methods of biopsy. Meanwhile, the most preferred methods are shaved and punch biopsies. Punch biopsy is used more often in even morphea-form BCC or in recurrent BCC. ${ }^{1,4}$ The treatment of $\mathrm{BCC}$ is chosen based on the anatomical location and tumor characteristic, such as size, location and type. Several therapies for BCC are Mohs micrographic surgery (MMS) or radiation therapy, electrodessication and curettage, cryosurgery, $\mathrm{CO}_{2}$ laser ablation, photodynamic therapy and wide excision surgery. ${ }^{1,5}$

\section{CASE REPORT}

A 48-year-old male came to dermato-venerology clinic at one of private hospital in Bali with a chief complaint of having a wound on his left shoulder since a year before. At first, it was just a small skin lump and red, but gradually he felt it getting larger and turned black at the center of the wound. He denied any history of trauma, pain or itchy sensation. There was no discharge, blood or pus coming out of it. He routinely applied topical corticosteroid but it never got better. Patient had lived in Indonesia since a year before and often got exposed to the sun. He surfed regularly after arriving in Indonesia and he was a smoker since several years before. There was no history of previous illness or malignancy in either him or his family members.

On physical examination, a solitary erythematous nodule was found with a size of $1.0 \mathrm{~cm} \times 1.0 \mathrm{~cm}$ on his left upper arm, surrounded by erythema skin. In the center, there is an ulcer covered with black crust. Dermoscopy examination also has been done and the results show erythema nodule with irregular border, arborizing micro vessels, short fine telangiectasis, and small erosions with necrotic tissue (Figure 1). This description indicated a basal cell carcinoma.

After that, he underwent an elliptical standard excision. The result of histopathology showed cell proliferation which matched the description of basaloid cell and shaped like different-sized solid islands. Some showed necrotizing en masse in the center. In addition, there was also a picture of basaloid cells arranged palisading at the edges, a picture of multi-focal superficial nest attached to the basal part of the epidermis, and the presence of basaloid 
cell foci that showed differentiation towards the follicular infundibulum. These findings suggest a mixed type of basal cell carcinoma (ulcerative, solid nodular, infundibulocystic, and superficial multifocal type). This histopathological examination was confirmed by the pathology department at the hospital.

Based on the anamnesis, physical and histopathological examinations, the final diagnosis of this case is mixed type basal cell carcinoma (ulcerative, solid nodular, infundibulocystic, and superficial multifocal type). The patient's lesions were subjected to standard excision suggest under local anesthesia. The histopathological results confirmed that the lump that the patient complained about was a mixed type of basal cell carcinoma (Figure 2). The post wide excision wound was closed with both outer and inner sutures. After 2 weeks, the patient came back to the clinic to remove the stitches, and it looked dry, without any signs of infection. Patients were also required to re-evaluate within 6 months, to prevent the appearance of other skin malignancies.

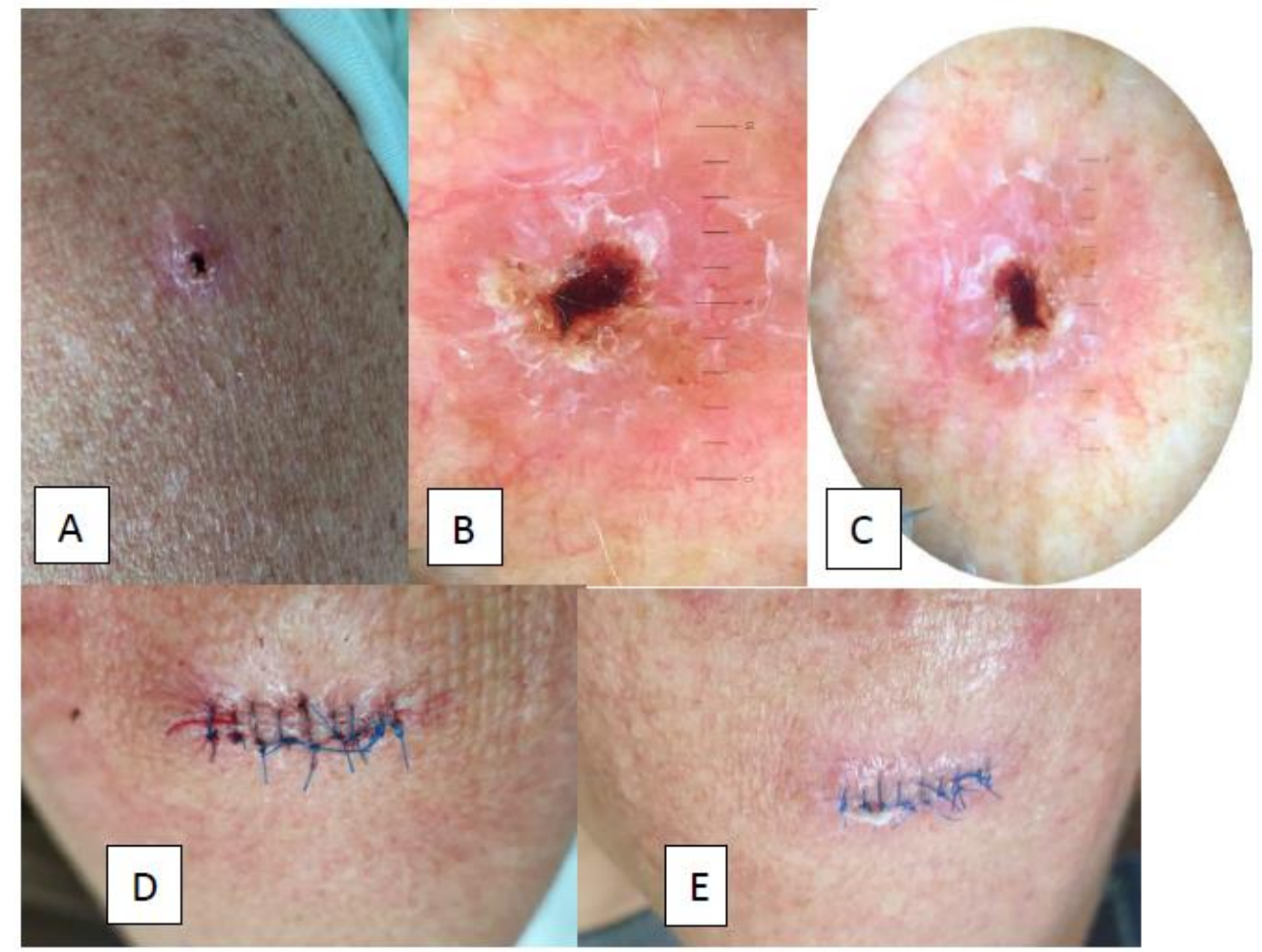

Figure 1. Basal cell carcinoma lesions before and after wide excision

A. Macroscopic of basal cell carcinoma, B and C. Dermoscopy of basal cell carcinoma C. After wide excision D. After 2 weeks wide excision

\section{DISCUSSION}

From the patient's history, there was a complaint of skin lump on the left shoulder since a year ago, it has wound on the area, the wound is getting wider and the color changes to black. The wound never heals properly. This condition can be suspected of leading to basal cell carcinoma, where the basal cell carcinoma lesions have characteristics that will continue to develop even for a long time, eventually invading local tissues. Risk factors for BCC are white people, men, history of sun exposure or ultraviolet rays, immunosuppression, smoking, radiotherapy and a family history of skin cancer. In this patient the risk factors are male, white skin, smokers and a history of frequent sun exposure. ${ }^{1,4}$

On physical examination, there was a solitary erythematous nodule around 1.0 $\mathrm{cm} \times 1.0 \mathrm{~cm}$ on the upper left arm, surrounded by erythematous skin. In the center area there is ulcer covered with black crust. From this physical examination, the 
clinical features found suggest that of basal cell carcinoma, Dermoscopic examination has also been done, we found erythema nodule with irregular border, arborizing micro vessels, short fine telangiectasis, and small erosions with necrotic tissue (Figure 1). Dermoscopy features in this patient are within the characteristics dermoscopy features found in BCC. Ulcerations, maple leaf-like areas, large grey-blue ovoid nests, multiple grey blue globules, spoke wheel areas, and arborizing telangiectasia were found to be dermoscopic criteria significant for the diagnosis of pigmented BCC. ${ }^{9,10}$ Thick branched vessel resemble the branches of a tree therefore named arborizing vessels. ${ }^{10}$ In Emiroglu study, arborizing vessels can be found in $33.3 \%$ of pigmented BCCs, and in $23.5 \%$ of pigmented subtypes of mixed BCCs. ${ }^{11}$ Telangiectasia is a red dilated linear vessels without branching. Blue-gray ovoid nests is well circumscribed, confluent or nearly confluent pigmented ovoid or elongated areas, larger than globules and not intimately connected to a pigmented tumor body. Their color can show different shades of gray and blue. Multiple blue-gray dots/globules, globules are an ovoid or round structure smaller than nests and larger than dots, while dots are round, punctuate structures, smaller than globules. Maple leaf-like areas is a brown to gray/blue discrete bulbous structures forming leaf-like patterns. They are like discrete pigmented nests-islands. Spoke-wheel areas is well circumscribed radial projections, usually tan in color but sometimes blue or gray, meeting at an often-darker central axis. Spoke-wheel areas and leaf-like areas is a rare, but these features are considered in general as an exclusive feature seen in superficial BCC. ${ }^{10} \mathrm{~A}$ further important hint in the diagnosis of superficial BCC might be found in the presence of small ulcerations, which appear on dermoscopy as red to brown homogenous structureless areas. This condition is due to loss of epidermis skin layer which is often covered by hemorrhagic crusts as in the dermoscopy features of this patient. Each subtype of BCC has a different and typical dermoscopy features, therefore dermoscopy examination can help us in establishing the diagnosis of BCC.

So, from patient's history, he has been having redness skin lump for 1 year ago. The wound felt wider and there was a change in color to blackish. On physical examination, there was a solitary erythematous nodule around $1.0 \mathrm{~cm} \times 1.0 \mathrm{~cm}$ on the upper left arm, surrounded by erythematous skin, and in the center area there is ulcer covered with black crust. Dermoscopy examination has also been performed and show erythema nodule with irregular border, arborizing micro vessels, short fine telangiectasis, and small erosions with necrotic tissue (Figure 1). From all patient's history and examination, we suggestive to basal cell carcinoma. However, to further prove the current diagnosis, we performed standard excision under local anesthesia, and then, a biopsy was performed to determine the histology.

Standard elliptic excision under local anesthesia was performed, and histopathological results confirming the diagnosis of mixed-type basal cell carcinoma. Mixed types of BCC in this patient were ulcerative, solid nodular, infundibulocystic, and superficial multifocal types. The most common BCC is nodular type, approximately (50-80\%) and mostly occurs in areas that are frequently to sunlight. ${ }^{1}$ Each type of basal cell carcinoma has its own characteristics. The clinical manifestations of $\mathrm{BCC}$ are divided into several subtypes, such as nodular form, morphea form, pigmented, and fibroepithelioma of pinkus (FOP $)^{1}$. The characteristics of nodular $\mathrm{BCC}$ is papules and nodules that resemble pearls, translucent accompanied by telangiectasia typical, arborizing vessel on dermoscopic examination. Arborizing vessels Arborizing vessels were found in $75 \%$ cases of nodular BCC. ${ }^{1,4,10}$ In its development, ulcerations can occur in the central area and covered with crusts, these ulcers are called rodent ulcers. With this ulcer it gives a sign that a 
chronic process has occurred that lasts for months or even years. Superficial BCC most commonly appears on the trunk with welldemarcated erythematous patch. The differential diagnosis includes SCC, lichenoid keratosis, and nummular dermatitis. An isolated patch of "eczema" that does not respond to treatment should raise suspicion for superficial BCC. Superficial BCC is characterized microscopically by buds of malignant cells extending into the dermis from the basal layer of the epidermis, minimal dermal involvement. ${ }^{1} \quad$ From dermoscopy examination superficial BCC is characterized a superficial fine telangiectasis and multiple small erosions. Nodular BCC has another subtype, the other type is pigmented BCC. Pigmented means an increase in melanin. Pigmented BCC appears as a hyperpigmented, translucent papule. The differential diagnosis includes nodular melanoma and seborrheic keratosis. The features of pigmented BCC based on histologic is nodules of basophilic nests with melanocytes interspersed between tumor cells; melanophages within stroma. ${ }^{1}$ Most commonly on the face and neck. ${ }^{7}$ Dermoscopy result show a spoke wheel area, leaf like area, and blue gray ovoid nests. ${ }^{9}$ This BCC must be distinguished from other pigmented lesions, such as malignant melanoma. We can use Menzies method for diagnosing melanoma the pigmented lesions, both of the following negative features must not be found: a single color and point and axial symmetry of pigmentation. Additionally, at least one positive feature must be found. The positive features are pseudopods, blue-white veil, radial streaming and multiple color. ${ }^{9,10}$

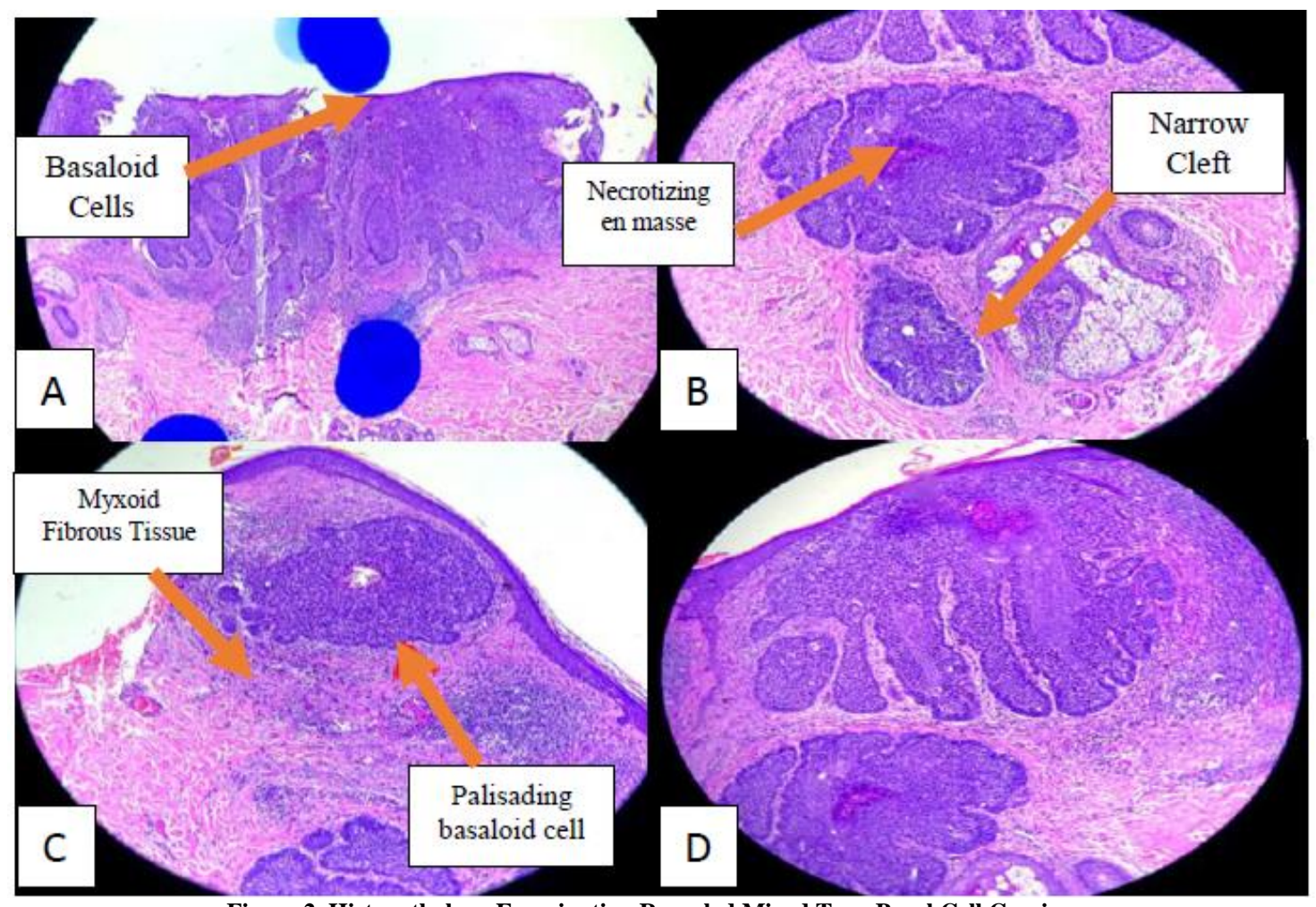

Figure 2. Histopathology Examination Revealed Mixed Type Basal Cell Carcinoma (ulserative, solid nodular, infundibulocyctic, dan superficial multifocal type)

The aggressive growth variant of BCC with the most different clinical and histologic appearance is the morphea form. Morpheaform BCC have an ivory-white appearance likes a scar or small lesion of morphea. Morpheaform BCC consists of strands of tumor cells embedded within a dense fibrous stroma. ${ }^{1}$ Dermoscopic will show a superficial fine telangiectasis feature. $^{7,11}$ Fibroepithelioma of Pincus 
(FOP) presents as a pink papule on the lower back. It may be difficult to distinguish from an acrochordon or skin tag. In FOP, long strands of interwoven basiloma cells are embedded in fibrous stroma with abundant collagen. Most commonly on the extremities and genitalia region., ${ }^{1,7}$ Dermoscopy of FOP will found arborizing vessels and white streaks area. ${ }^{11}$

Surgical excision and MMS followed by histopathological confirmation are the gold standard for high-risk BCC. ${ }^{1,5}$ The main objective of these BCC procedures is to completely remove the tumor. In this case, the patient was subjected to standard elliptic excision because the neoplasm was small to moderate in size and the location of the neoplasm was in the extremities, and elliptical excision provided good cosmetics by minimizing tissue removal, skin movement and incision length. There are many treatments that can be given to patients with BCC. To determine the most appropriate treatment modalities, it must be evaluated based on an assessment of the relative risk of recurrence of an individual lesions. The modalities treatment that can be given are topical therapy for low-risk disease, minimally invasive procedures with destructive modalities, and specialized modalities such as radiotherapy, MMS, and surgical excision. This special modality is indicated for high-risk BCC.

The important things to prevent $\mathrm{BCC}$ incident is that everyone must know the risk factors that can cause BCC, early diagnosis, and adoption of preventive measures, especially in susceptible populations. Due to evidence of involvement of $\mathrm{UV}$ rays on $\mathrm{BCC}$ development, it is mandatory to use sun protection in people who are exposed to the sun frequently and they have to get information about times of lower incidence of UVB, occupational and leisure protection, prevention of sunburn, use of appropriate clothing, hats, protective films for cars and use of a broad-spectrum sunscreen. ${ }^{11}$
The prognosis in patients with basal cell carcinoma is generally good, patients should be followed up after the procedure to rule out recurrences. The risk of recurrence is around $36 \%-50 \% .^{1}$ Thus, patients with basal cell carcinoma should always have periodic full skin examinations and it is always advisable to use sun protection.

\section{CONCLUSION}

Basal cell carcinoma may happen to everybody, especially in white-skinned people and a history of sun exposures or ultraviolet. Diagnosis of the patient is made from anamnesis, physical examination, dermoscopy and histopathology examination - which is taken from the standard management of elliptical standard excision. From all examinations, we can find characteristics that matched with criteria of basal cell carcinoma.

\section{Conflict Of Interests}

There is no personal or institutional interest regarding this article.

Funding: None.

\section{Authors' Contribution}

All of authors are equally contributed to the study.

\section{REFERENCES}

1. Tang JY, Epstein EH, Oro AE. Basal Cell Carcinoma and Basal Cell Nevus Syndrome. In: Kang S, Amagai M, Bruckner AL, Enk AH, Margolis DJ, et al. Fitzpatrick's Dermatology. $9^{\text {th }}$ ed. New York: McGraw Hill Education; 2019. P1884.

2. Lomas A, Leonardi-Bee J, Bath-Hextall F. A systematic review of worldwide incidence of nonmelanoma skin cancer. $\mathrm{Br} \mathrm{J}$ Dermatol. 2012;166(5):1069-80.

3. Arisanty R, Tanurahardja B. Profil Keganasan Primer Kulit Tersering di Departmenen Patologi. Vol 20. Jakarta: FKUI; 2011. P14-20.

4. Cipto H. Tumor Kulit. In: Menaidi SLSW, Bramono K, Indriatmi K. Ilmu Penyakit Kulit dan Kelamin $7^{\text {th }}$ ed. Jakarta: FKUI; 2019. P269-270. 
5. Telfer NR, Colver GB, Morton CA, British Association of Dermatologists' Guidelines for the management of basal cell carcinoma. Br J Dermatol. 2008;159(1):35-48.

6. Wong CSM, Strange RC, Leat JT. Basal cell carcinoma. BMJ. 2003; 327(7418): 794-98.

7. Chinem VP. Epidemiology of basal cell carcinoma. An Bras Dermatol. 2011; 86: 292-305.

8. Lewin JM. Carucci JA. Advanced in the management of basal cell carcinoma. Prime Report. 2015;7:1-8

9. Braun RP, Rabinovitz HS, Oliviero M, dkk. Dermoscopy of pigmented skin lesions. J Am Acad Dermatol. 2005; 52: 109-21.

10. Trigoni A, Lazaridou E, Apalla Z, Vakirlis E, Chrysomallis, Varytimiadis D, dkk.
Dermoscopic feature in the diagnosis of different types of basal cell carcinoma a prospective analysis. Hippokratia. 2012;16: 29-34.

11. Emiroglu N, Kemeriz F. The relation between dermoscopy and histopathology of basal cell carcinoma. An Bras Dermatol. 2015; 90: 351-6.

How to cite this article: Suma Pratiwi Tanoto, Gusti Ayu Vina Mery Giovani. Mixed type basal cell carcinoma in 48 years old Caucasian male: a case report. International Journal of Research and Review. 2022; 9(2): 254-260. DOI: https://doi.org/10.52403/ijrr.20220235 